\title{
Service Quality of Language Institute and Eastern Wisdom
}

\author{
Dr. Watchara Yeesuntes, and Xiaomeng Hua \\ watchara.yee@kbu.ac.th \\ Post Graduate School of business administration, Kasembundit University, Bangkok
}

\begin{abstract}
The primary purpose of the study was to determine factors affecting service quality of Language Institute and Eastern wisdom. The population of this study were 100 students who study at Language Institute and Eastern wisdom by using questionnaire as a tool. The statistics used for data analysis were percentage, mean, standard deviation, t-test, One-way Anova, and regression analysis.

Finding indicated that most of respondents were females, age 15-19 years old, student occupation, received information of Language Institute and Eastern wisdom from newspapers and magazines, and period of language study for 6 years. The overall picture of the opinionon factorsthat affected service quality of Language Institute and Eastern Wisdom were in high level, such as tangible services, customer relationship, care, and understand customer required.The factors of personal difference, such as gender, age, occupation, information source, and learning period were not affected Service Quality satisfaction of Language Institute and Eastern Wisdom. Factors of service quality correlated with Service Quality satisfactionof Language Institute and Eastern Wisdom which consisted of tangible service, clearly and visible sign of Language Institute, response to customer request, courtesy and well manners with significant 0.05 level.

Recommendations from this study were that administrative officers should prioritize on service quality of all personnel at all levels, modern technology equipment, develop service quality in order to meet customer demand.
\end{abstract}

Keyword: Service Quality

\section{Introduction}

Presently, the population around the world began to learn Chinese language which is important in communication in society. Now, Thai people have been learnt Chinese language increasingly. Not only, there are Chinese tutorial schools, but also more Chinese language Institute are open, where the quality of the service or teaching is important, and that is the problem for people who search for the right tutorial institutions.

To impress the customers with quality and value in the service, the important factors and necessary for businessare customer service which service quality delivery to them, assuming the impression of service excellence to our customers and generate the output from services delivery, customer satisfaction and relationships with customers, including images to encourage these customers to come back to purchase goods or services, as well as to build customer relationships and long-term loyalty to our product or service forever.

Servicing means the service provider or seller deliver the service to the recipient or the buyer, service are intangible, but when patients receive services satisfaction with us by doing whatever it takes to add new customer, to create prosperity with the number of customers increased as new indicators.Services are intangible and insubstantial: they cannot be touched, gripped, handled, looked at, smelled, and tasted. Thus, there is neither potential nor need for transport, storage or stocking of services. Furthermore, a service can be (re)sold or owned by somebody, but it cannot be turned over from the service provider to the service consumer. Solely, the service delivery can be commissioned to a service provider who must generate and render the service at the distinct request of an authorized service consumer.

The service relevant resources, processes and systems are assigned for service delivery during a definite period in time. If the designated or scheduled service consumer does not request and consume the service during this period, the service cannot be performed for him. From the perspective of the service provider, this is a lost 
business opportunity as he cannot charge any service delivery; potentially, he can assign the resources, processes and systems to another service consumer who requests a service. Examples: The hairdresser serves another client when the scheduled starting time or time slot is over. An empty seat on a plane never can be utilized and charged after departure.

One of the most important characteristics of services is the participation of the customer in the service delivery process. A customer has the opportunity to get the services modified according to specific requirement.

Each of these characteristics is retractable per se and their inevitable coincidence complicates the consistent service conception and make service delivery a challenge in each and every case. Proper service marketing requires creative visualization to effectively evoke a concrete image in the service consumer's mind. From the service consumer's point of view, these characteristics make it difficult, or even impossible, to evaluate or compare services prior to experiencing the service delivery.

From the above information, researcher was interested in studying the quality of service of the Institute for language and Eastern wisdom,results can be used as a guidelines to improve the quality of the service, in accordance with the requirements of the consumer.

\section{Purpose of the study}

The primary purpose of the study was to determine factors affecting service quality of Language Institute and Eastern wisdom.

\section{Conceptual Frameworks of the Study}

The primary purpose of the study was to determine factors affecting service quality of Language Institute Eastern wisdom and to guide in the development of quality services to meet the requirements of the customer.

\section{Research Methodology}

\subsection{Sample selection}

The samples were 100 customers at Chinese language Institute and Eastern wisdom, Central Department store, Changwattana branch.

\subsection{Data collection procedure}

The questionnaires were distributed to sample of 100 Chinese language Institute and Eastern wisdom, Central Department store, Changwattana branch. A total of 100 usable questionnaires were returned back to the researcher, yielding a 100 percent response rate and no missing data.

\section{Results}

Finding indicated that most of respondents were females, age 15-19 years old, student occupation, received information of Language Institute and Eastern wisdom from newspapers and magazines, and period of language study for 6 years.

Factors that affect the service quality of the teachers at Institute of language and Eastern wisdom.

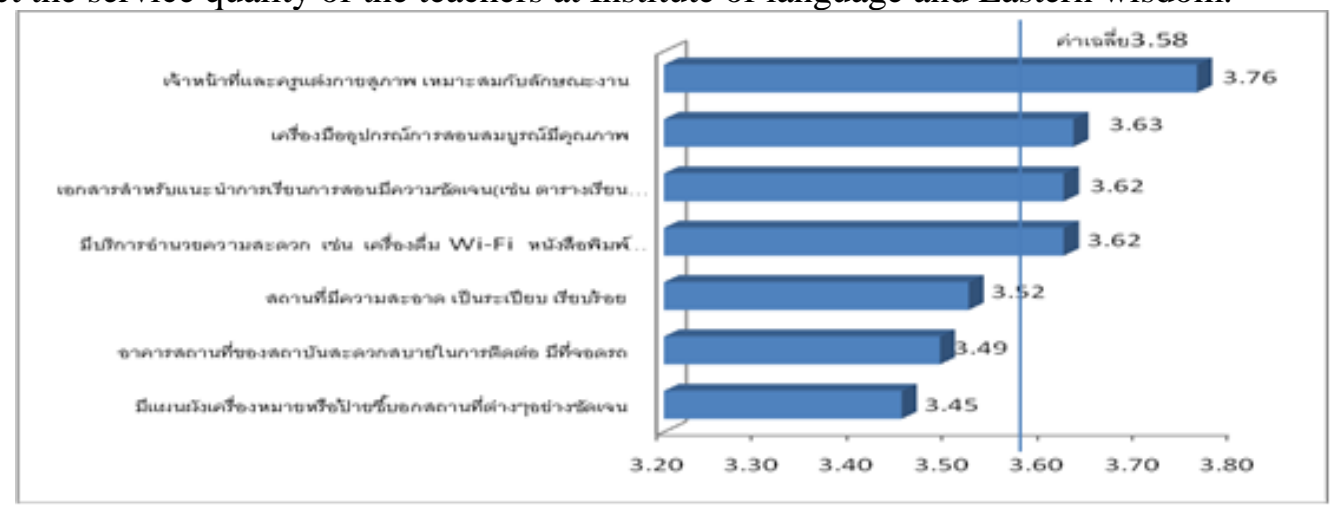

Fig. 1 
From figure 1: Factors that affected the service quality of the Institute of language and Eastern wisdom of tangible services aspect were at the high level with following details: teachers and office personnel dressed properly that appropriate to work $(\bar{x}=3.76)$, well equipped with teaching instrument $(\bar{x}=3.63)$, registration, class schedules well prepared $(\bar{x}=3.62)$, offer convenient facility, such as Wi-Fi and beverages, magazines, and newspapers $(\bar{x}=3.62)$, cleanliness facility $(\bar{x}=3.52)$, easy access to Chinese Language Institute $(\bar{x}=3.49)$, well prepared class syllabus document $(\bar{x}=3.45)$ with the average picture of the opinions of factors affecting service quality of Language Institute and Eastern Wisdom concerning tangible service were in high level $(\bar{x}=3.50)$.

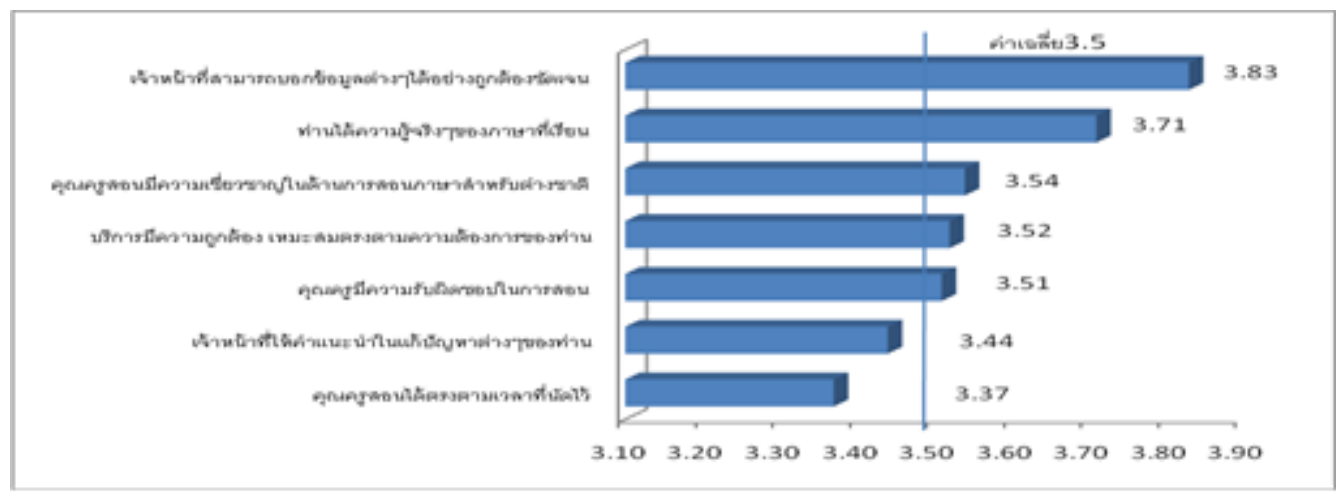

Fig. 2

From figure 2: Factors that affected the service quality of the Institute of language and Eastern wisdom of dependability aspect were at the medium level with following details: knowledgeable personnel $(\bar{x}=3.83)$, received real knowledge $(\bar{x}=3.71)$, expert teachers who have experience in teaching Chinese language to foreigners $(\bar{x}=3.54)$, appropriate services as expected $(\bar{x}=3.52)$, teaching responsibility $(\bar{x}=3.51)$, personnel assistant in solving problem $(\bar{x}=3.44)$, on time as appointment $(\bar{x}=3.37)$ with the average picture of the opinions of factors affecting service quality of Language Institute and Eastern Wisdom concerning dependability aspect were in high level $(\bar{x}=3.58)$.

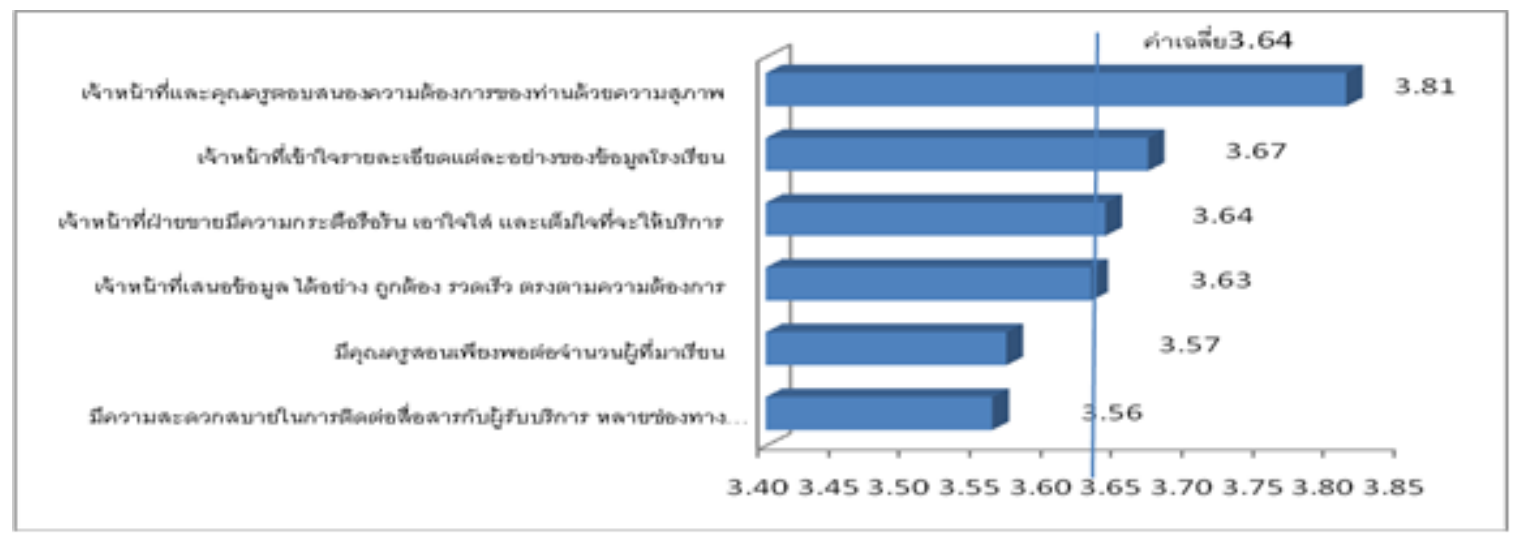

Fig. 3

From figure 3: Factors that affected the service quality of the Institute of language and Eastern wisdom of service response aspect were at the high level with following details:service with courtesy personnel $(\bar{x}=3.81)$,personnel with full understanding of operation $(\bar{x}=3.67)$, sale personnel are willing to service $(\bar{x}=3.64)$, accurately information given $(\bar{x}=3.63)$, adequate teachers to handle number of students $(\bar{x}=3.57)$, there are convenient to get informationfrom difference sources, such as email, Facebooks, and school board (3.56) with the average picture of the opinions of factors affecting service quality of Language Institute and Eastern Wisdom concerning consumer service response aspect were in high level $(\bar{x}=3.64)$. 


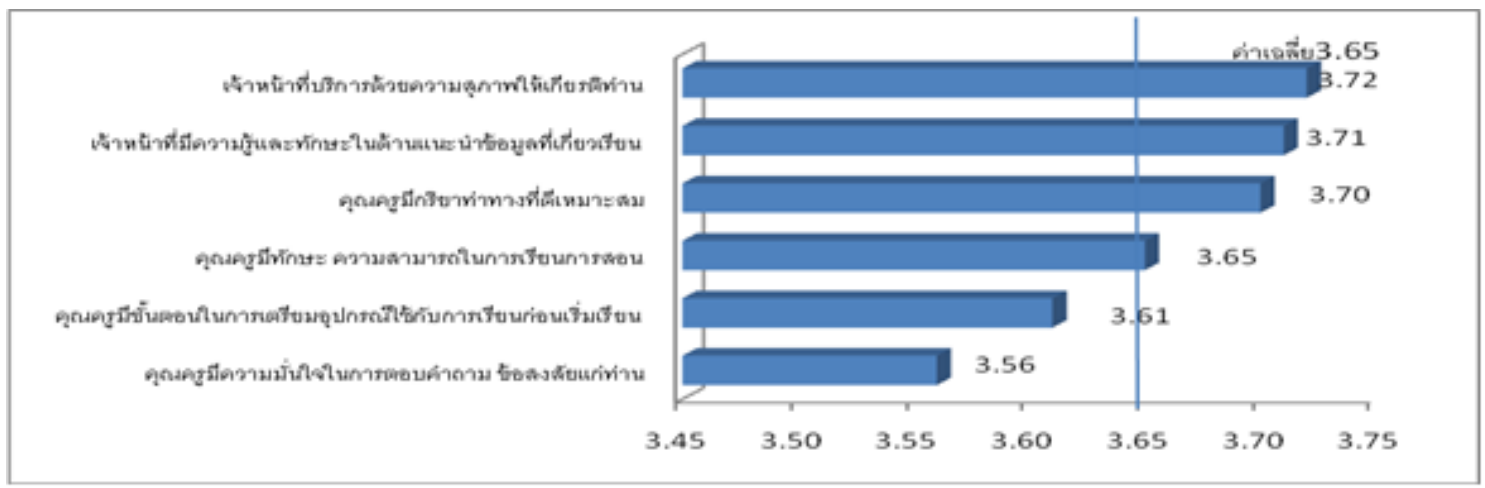

Fig. 4

From figure 4: Factors that affected the service quality of the Institute of language and Eastern wisdom of reliability aspect were at the high level with following details: service with courtesy personnel $(\bar{x}=3.72)$, personnel with full understanding of operation $(\bar{x}=3.71)$, respectablemanners teachers $(\bar{x}=3.70)$, teacher with good ability to teach $(\bar{x}=3.65)$, teachers prepared teaching tools before class start $(\bar{x}=3.61)$, teachers answer question with confidence $(\bar{x}=3.56)$ with the average picture of the opinions of factors affecting service quality of Language Institute and Eastern Wisdom concerning reliability aspect were in high level $(\bar{x}=3.65)$.

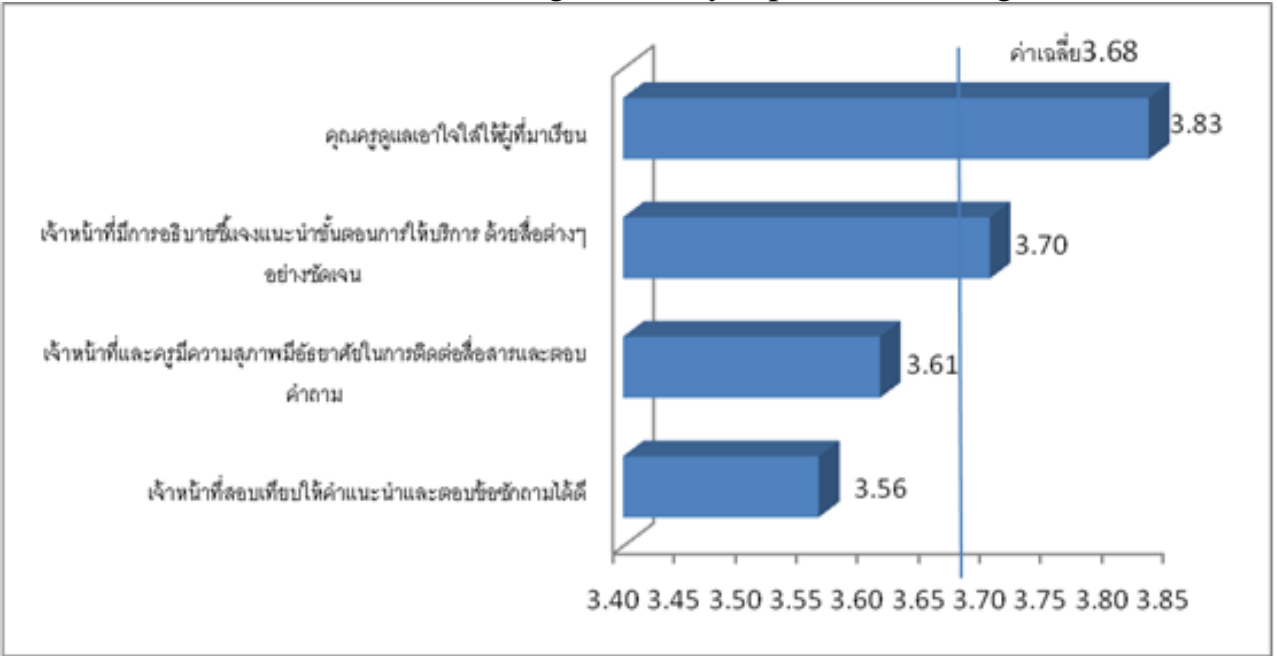

Fig. 5

From figure 5: Factors that affected the service quality of the Institute of language and Eastern wisdom of considerate and servicing aspect were at the high level with following details: teacher pay attention to students $(\bar{x}=3.83)$, school personnel explain details of information with technology devices $(\bar{x}=3.70)$, personnel with courtesy to answer $(\bar{x}=3.61)$, personnel give advice with comprehensible $(\bar{x}=3.56)$ with the average picture of the opinions of factors affecting service quality of Language Institute and Eastern Wisdom concerning considerate and serving aspect were in high level $(\bar{x}=3.68)$.

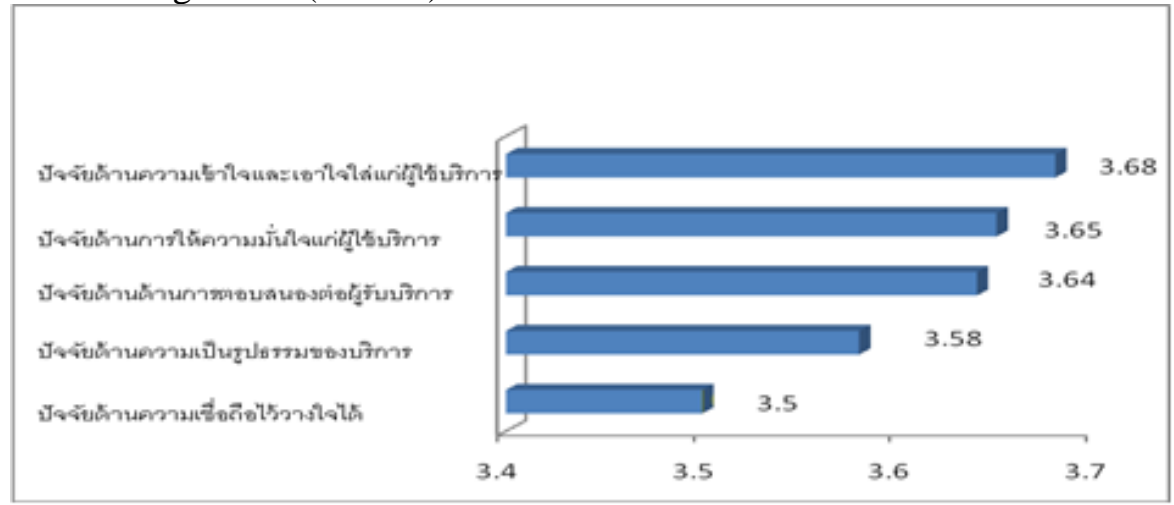

Fig. 6 
From figure 6: Factors that affected the service quality of the Institute of language and Eastern wisdom were at the high level with following 5 aspects: such as concerning considerate and serving aspect were in high level $(\bar{x}=3.68)$, concerning reliability aspect were in high level $(\bar{x}=3.65)$, consumer service response aspect were in high level $(\bar{x}=3.64)$, tangible service were in high level $(\bar{x}=3.58)$, and dependability aspect were in medium level $(\bar{x}=3.50)$, respectively. The average picture of opinions regarding service quality of Language Institute and Eastern Wisdom consisting of 5 aspects was in the high level $(\bar{x}=3.61)$.

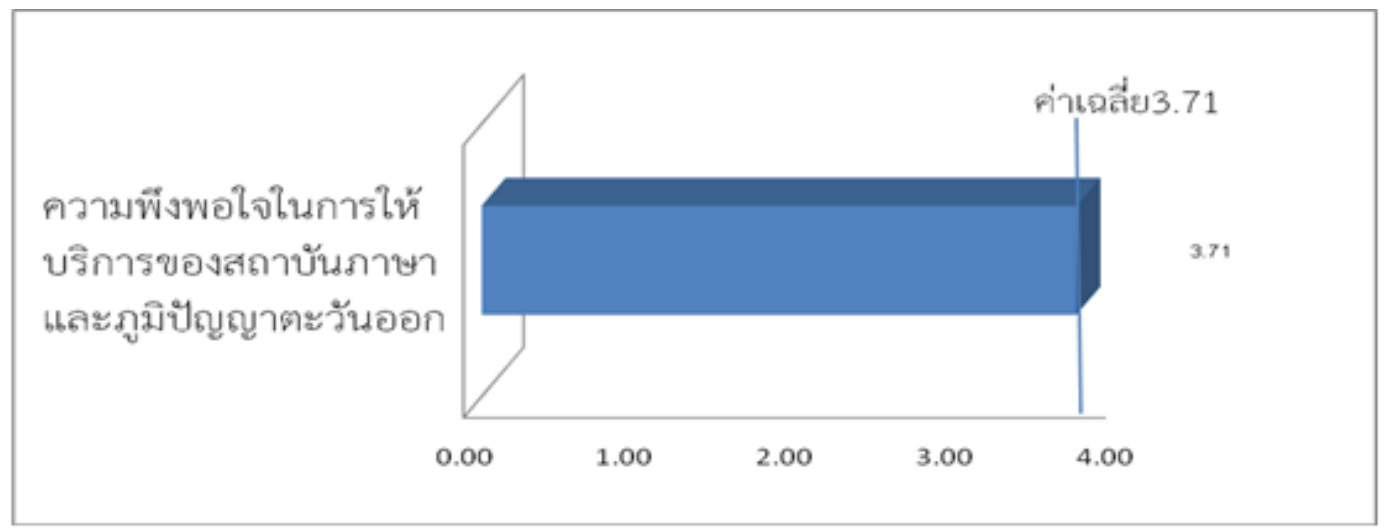

Fig. 7

From figure 7: From the study revealed that overall picture of service quality of Chinese language Institute and Eastern wisdom were in high level $(\bar{x}=3.71)$

\section{Results}

Finding indicated that most of respondents were females, age 15-19 years old, student occupation, received information of Language Institute and Eastern wisdom from newspapers and magazines, and period of language study for 6 years. The overall picture of the opinion on factors that affected service quality of Language Institute and Eastern Wisdom were in high level, such as tangible services, customer relationship, care, and understand customer required. The factors of personal difference, such as gender, age, occupation, information source, and learning period were not affected Service Quality satisfaction of Language Institute and Eastern Wisdom. Factors of service quality correlated with Service Quality satisfaction of Language Institute and Eastern Wisdom which consisted of tangible service, clearly and visible sign of Language Institute, response to customer request, courtesy and well manners with significant 0.05 level.

\section{Suggestion from the Study}

Recommendations from this study were that administrative officers should prioritize on service quality of all personnel at all levels, modern technology equipment, develop service quality in order to meet customer demand.

\section{References}

[1] TaveesakThippitak. (2550). Logistics and supply chain management. Expertnet publisher, Bangkok.

[2] VeeraphongChalernjirarat. (2539). Service quality management, Technology supportingAssociation (Thai \& Japan) Bangkok.

[3] ChaisompongChaoprasert. (2548). Market service. CSU cation publisher, Bangkok.PimrampaiPremsamit. (2535) "Service efficiency assessment of the Library" Journal of academic service. June 14.

[4] PanvadeeApisupachoke. (2547). Service quality development of Education department LibraryBy using Libqual+TM integration and model of Kano to QFD, Graduate level, Chulalongkorn University, Bangkok (copy).

[5] Integrating the LibQUAL + TM , and a replica of the Canopus (Kano's Model) to QFD. graduate of Chulalongkorn University., Bangkok (copy) .

[6] SiriwanSaereerat. (2546). New era of marketing management. Thammasarn publisher, Bangkok. 
[7] VeeraratKijlertpairoj. (2547). Marketing service. CS Ucation publisher, Bangkok.

[8] AnakSuwanbundit. (2548). Psychology services. Press and design publisher, Bangkok.

[9] ChindaratBurphan. (2543). Service information quality, Journal of Library 20(1): 45-48: January.

[10] SupatSongsangchan. (2547). "Thebasis of service quality" Library Journal 48 (1): 1-14; January- March.

[11] NayikaDudkhuntod. (2549). The Library and quality service. Journal of information, 13 (2) .70-84. July-December.

[12] ManusaveeTadasri\& Associate. (2545). High quality service. Maxpro Consultant.

[13] JittinunDechakup. (2530). Psychology services. Sukhothaithammatirach publisher, Nonthaburi.

[14] VithayaDanthumrongkul. (2547). CRM-CEM Yin Yang Market, Vonggrom publisher, Bangkok. 